\title{
The changing face of Canadian immigration: Implications for infectious diseases
}

\author{
BL Johnston $M D^{2}$, JM Conly $M D^{1}$
}

$\mathrm{I}$

In the May/June issue of The Canadian Journal of Infectious Diseases 87 Medical Microbiology, in the Adult Infectious Disease Notes section, two infectious diseases that were frequently seen in the "Lost Boys and Girls of Sudan" were reviewed (1). However, the Sudanese refugees represent only a very small proportion of the immigrant population, many of whom experience other significant infections and resettlement issues. In the present issue, we consider the changing face of Canadian immigration and how that impacts infectious disease clinicians.

While they represent just fewer than $1 \%$ of the Canadian population, the number of immigrants to Canada more than doubled between 1986 and 2006, increasing from 99,351 per year to over 251,649 per year, respectively (2). A similar number of individuals entered Canada in 2006 as temporary residents, and the majority entered as temporary foreign workers or students (3). If Canadian population growth continues to decline as expected, the proportion of the population represented by immigrants and temporary residents will continue to increase.

Concomitant with this growth in immigration has been a distinct change in the composition of the immigrant population, with the biggest shift beginning after approximately 1971. Immigrants from Europe represented $75.9 \%$ of the total immigrant population in 1921, 79.4\% in 1971 and $42 \%$ in 2001 (4). Asians, who represented 2.7\% in 1921 and $3.6 \%$ in 1971 , were up to $36.5 \%$ of the immigrant population in 2001 (4). From essentially $0 \%$ in 1921 to $1 \%$ to $2 \%$ in 1971, those from the Caribbean, Latin America and Africa each represented $5 \%$ of the immigrant population in 2001 (4). In 2004, refugees accounted for $13.9 \%$ of immigrants (4). From within Asia, China was the leading country of birth for new immigrants in 2001, followed closely by India (5). Among African immigrants, Egypt was the leading country of birth for immigrants to Canada in 2001, followed closely by South Africa (6).

More than $50 \%$ of immigrants in 2002 settled in Ontario, and $43.7 \%$ of Toronto's metropolitan population in 2001 was foreign-born (4). Almost $80 \%$ of Asian immigrants lived in Ontario and British Columbia in 2001, with a similar proportion of African immigrants living in Ontario and Quebec $(5,6)$. Foreign-born persons account for fewer than $5 \%$ of the metropolitan population in Atlantic Canada, but 37.5\% of the population in metropolitan Vancouver, British Columbia (4). Unfortunately, in Canada, $42.4 \%$ of immigrant children live in poverty, similar to the poverty rate among Aboriginal children in Canada (4).
Although the immigration patterns have changed over the years, they are still quite different from one part of the country to the other. More of the immigrants are coming from countries with high rates of certain infectious diseases. The poor socioeconomic conditions faced by many of them during their initial settlement phase places them at continued risk for certain infectious illnesses (7). How well are infectious disease clinicians able to address their health concerns?

Several groups have reported their experience with illnesses diagnosed in immigrants and/or refugees. An epidemiological survey (8) was conducted in 46 Italian health centres in 2002, examining the number and type of hospital and outpatient clinic admissions among immigrants. They evaluated 2555 immigrants (6\% of the total patient population), of whom $44 \%$ were from Africa, 20\% from Asia and $22 \%$ from eastern Europe. The three main infectious diseases seen were HIV infection (16.8\%), tuberculosis ([TB]; 13.4\%) and viral hepatitis $(12.5 \%)$, with so-called tropical infections (eg, malaria, dengue and schistosomiasis) seen in only $5.8 \%$ of admissions in immigrants, the majority $(70.4 \%)$ of whom had malaria (8). HIV and TB were most common in African immigrants, whereas eastern Europeans accounted for the largest proportion of viral hepatitis (8). To put this into the larger context of health-related concerns among immigrants, Sabbatani et al (9) analyzed admissions to a general teaching hospital in Bologna, Italy, over five years beginning in 1999. Foreign-born patients represented only $2.2 \%$ of total hospitalizations ( $5 \%$ of the total population), of which only $12.1 \%$ of the hospitalizations were due to infectious diseases, either alone or with concurrent disorders (9). In that catchment area, most immigrants came from North Africa (31.5\%), followed by Asia (26.3\%), eastern Europe (22\%) and subSaharan Africa (7.4\%) (9).

An Australian study by O'Brien et al (10) had somewhat different findings. They prospectively studied 189 immigrants and refugees from January 1, 1997, to September 30, 2004. The majority were from Africa (43\%) and Asia (42\%). The most common diagnoses were TB (50\%), schistosomiasis (13\%), helminth infection (10\%) and chronic hepatitis (9\%). More specifically among refugees in New Zealand (almost one-half from the Middle East), Hobbs et al (11) found that $3.2 \%$ tested positive for schistosomiasis, $4 \%$ for chronic hepatitis and $13.2 \%$ for other helminths; $36.4 \%$ had latent TB. The observed differences in prevalence of infection are, no doubt, related in large part to the proportionate differences in the country of origin, and in part to the intensity of the investigations undertaken.

\footnotetext{
${ }^{1}$ Queen Elizabeth II Health Sciences Centre and Dalhousie University, Halifax, Nova Scotia; ${ }^{2}$ Departments of Medicine, Pathology and

Laboratory Medicine, and Microbiology and Infectious Diseases, University of Calgary, Calgary, Alberta

Correspondence and reprints: Dr BL Johnston, Queen Elizabeth II Health Sciences Centre, 5014ACC - 1278 Tower Road, Halifax,

Nova Scotia B3H 2Y9. Telephone 902-473-5553, fax 902-473-7394, e-mail ljohnsto@dal.ca

Received and accepted for publication July 8, 2008
} 
Immigrants seen at one tropical medicine unit in Madrid, Spain, from 1989 to 2000 were offered a comprehensive battery of tests, including serology (hepatitis B, hepatitis C, HIV and syphilis), tuberculin skin test, three fecal samples for detection of ova and parasites, blood and skin samples for microfilariae, and for those from sub-Saharan Africa, blood smears for malaria (7). Of the 988 immigrants tested, $80 \%$ were from Africa, $16 \%$ from the Americas and 3\% from Asia. Latent TB was common (44\%) and did not differ among the different source regions (7). Filariasis was found in $24.8 \%$ of immigrants (almost entirely among the African immigrants). Intestinal parasites were detected in $23 \%$, with similar frequencies among the different immigrant groups, among whom $53 \%$ had eosinophilia (7). Only $27.3 \%$ of patients with intestinal parasites had gastrointestinal symptoms and 31\% were coinfected with several parasites. Chronic hepatitis was present in 16\% (hepatitis C $8.8 \%$ and hepatitis B 7.6\%), and HIV in $5 \%$. Twelve per cent of adults had malaria, $8 \%$ of whom had no symptoms.

Comprehensive data for Canada could not be found. However, Boggild et al (12) reported their prospective analysis of parasitic infections in immigrants and travellers who were seen at the Toronto General Hospital (Toronto, Ontario) tropical disease unit between November 1997 and June 2003. There were 1213 new immigrants or refugees in this cohort. While it is not possible to identify the exact disease frequency among the subgroups in this study, immigrants were more likely to be diagnosed with parasitic infections than were other travellers (12). Within the immigrant and visiting friends and relatives groups combined, $6.8 \%$ had malaria, 2.9\% strongyloidiasis, 2.7\% schistosomiasis and 2.1\% filariasis. Residence in Africa was associated with a higher risk of schistosomiasis and strongyloidiasis, whereas residence in the Far East was associated with clonorchiasis (12). Immigrants to Canada have undergone testing for HIV since 2001 (13). Of the 634,958 applicants (15 years of age and older) assessed in 2002 and 2003, $932(0.15 \%)$ tested positive (13). Of these, $67 \%$ were born in Africa, $22 \%$ in the Americas, $7 \%$ in Asia and 4\% in Europe; $70 \%$ were refugees (13).

The significance of schistosomiasis and strongyloidiasis in the Sudanese and Somali Bantu refugee groups is welldescribed (14), but the same may not be true for other immigrant populations. Pardo et al (15) prospectively evaluated 788 recent African adult immigrants to Spain, of whom 95\% were from sub-Saharan countries. A parasitic infection was diagnosed in $75.6 \%$, most frequently filariasis (29.6\%) followed by schistosomiasis (17.4\%), hookworm infection $(16.8 \%)$ and Trichuris species (8.4\%) infection. Strongyloides was found in only $2.3 \%$, but stool testing alone was performed (15). The country of origin was associated with specific diseases, and higher eosinophilic counts (median $1000 \times 10^{9} \mu \mathrm{L}$ ) were seen with filariasis (15). A Spanish study by Roca et al (16) found 200 cases (15.2\%) of schistosomiasis among 1321 African immigrants, almost 50\% of whom were asymptomatic and 30\% had nonspecific abdominal pain. Female genital schistosomiasis is a frequent complication in women with urinary or systemic schistosomiasis, and it may go undiagnosed in nonendemic countries where physicians are unlikely to be familiar with this syndrome (17).

In an HIV-infected population in the United Kingdom, screening for eosinophilia and parasites was undertaken in patients of African origin (18). Among the 51 patients with eosinophilia, 55\% had positive parasite serology compared with 9\% of control African HIV patients without eosinophilia. Thus, eosinophilia was a good marker for parasitic infection. However, $37 \%$ of patients with positive schistosomal serology had normal eosinophil counts when screened, indicating that infection may be present in the absence of eosinophilia (18). Microscopic diagnosis was made in only one of 89 specimens sent (47 urines and 42 stools), indicating poor test characteristics. These same investigators in an earlier study found that stool microscopy identified larvae in only $46 \%$ of immigrants diagnosed with Strongyloides on the basis of a positive stool and/or serology test, recognizing that one drawback to serology was its inability to distinguish current from remote infection (19). Thus, while Strongyloides prevalence rates may not be as high in other African populations as in the Sudanese and Somali refugees, the potential for infection has to be considered with a high index of suspicion and, when indicated, empirical treatment should be undertaken $(1,20)$.

The high proportion of immigrants with latent $\mathrm{TB}$ is evident $(7,10,11)$. The proportion of immigrants with active TB is also appreciable, ranging from $0.6 \%$ (11) to $13.4 \%$ (8) of individuals screened. While studies have demonstrated that immigrants and refugees have an increased likelihood of having reactivation disease in the first five years after their arrival in the United States, it has been debated whether this reflects an increased risk for progression of latent TB to active disease, an increased prevalence of latent $\mathrm{TB}$ in this group or an increased prevalence of active but undetected disease at arrival (21). This last hypothesis is supported by one study (22) in Switzerland demonstrating that new immigrants with TB were less likely to have clinical signs and symptoms of TB and positive results on rapid testing (sputum auramine-rhodamine fluorescent microscopy and polymerase chain reaction testing on concentrated decontaminated specimens) than were foreignborn and native residents. Knowing with certainty the reason for the increased rate of active TB among recent immigrants will help determine the most cost-effective approach to preventing its occurrence - tuberculin skin testing to identify latent TB or improved identification of active cases $(21,23)$.

Under Canadian immigration law, all immigration applicants must comply with medical screening requirements (13). These requirements are applied to all regular applicants for permanent settlement (immigrants and refugees) or temporary residence from designated countries, and refugee claimants (13). Applications for permanent residence will not be accepted if the person's health is a danger to public health or safety, or (apart from refugees, protected persons or certain individuals in the family class) would cause excessive demand on health or social services (24). For the most part, the specifics of the medical examination are not readily available. The Citizenship and Immigration Canada Web site (24) states that instructions on how to take the medical examination are normally sent after an application is submitted to the visa office, and that the medical examination must be performed by a designated medical practitioner. However, as noted, mandatory HIV serological testing began in January 2002 (13), and chest radiographic screening for TB has been performed since the 1940s (23). Syphilis testing is also required (T Kawchuk, personal communication). It appears that additional testing is left to the discretion of the designated medical practitioner or the immigrant's subsequent personal physician, depending on the clinical situation. 
In 2004, Gushulak and MacPherson (25) wrote that the impact of migration-associated changes in global infectious diseases epidemiology would have implications for those providing clinical infectious disease and laboratory diagnostic services. Two overriding needs were identified - international public health information, and an understanding of the immigration and

\section{REFERENCES}

1. Conly JM, Johnston BL.The infectious diseases implications of the "Lost Boys and Girls of Sudan". Can J Infect Dis Med Microbiol 2008; 19:215-6

2. Citizenship and Immigration Canada. Facts and figures $2006-$ immigration overview: Permanent residents. $<$ http://www.cic.gc.ca/ english/resources/statistics/facts2006/permanent/01.asp> (Version current at July 8, 2008).

3. Citizenship and Immigration Canada. Facts and figures $2006-$ immigration overview: Temporary residents. $<$ http://www.cic.gc.ca/ english/resources/statistics/facts2006/temporary/01.asp>. (Version current at July 8, 2008).

4. Canada Immigrant Job Issues. Volume \& structure. $<$ http://www.canadaimmigrants.com/statistics2.asp > (Version current at July 8, 2008).

5. Canada Immigrant Job Issues. Asian immigrants statistics. $<$ http://www.canadaimmigrants.com/Asia.asp $>$ (Version current at July 8, 2008).

6. Canada Immigrant Job Issues. African immigrants statistics. $<$ http://www.canadaimmigrants.com/Africa.asp $>$ (Version current at July 8,2008 ).

7. López-Vélez R, Huerga H, Turrientes MC. Infectious diseases in immigrants from the perspective of a tropical medicine referral unit. Am J Trop Med Hyg 2003;69:115-21.

8. Scotto G, Saracino A, Pempinello R, et al; Italian Study Group for Infectious Diseases in Immigrants. Simit epidemiological multicentric study on hospitalized immigrants in Italy during 2002. J Immigr Health 2005;7:55-60.

9. Sabbatani S, Baldi E, Manfredi R, Chiodo F. Admission of foreign citizens to the general teaching hospital of Bologna, northeastern Italy: An epidemiological and clinical survey. Braz J Infect Dis 2006;10:66-77.

10. O'Brien DP, Leder K, Matchett E, Brown GV, Torresi J. Illness in returned travelers and immigrants/refugees: The 6-year experience of two Australian infectious diseases units. J Travel Med 2006;13:145-52.

11. Hobbs M, Moor C, Wansbrough T, Calder L. The health status of asylum seekers screened by Auckland Public Health in 1999 and 2000. N Z Med J 2002;115:U152.

12. Boggild AK, Yohanna S, Keystone JS, Kain KC. Prospective analysis of parasitic infections in Canadian travelers and immigrants. J Travel Med 2006;13:138-44. migration process (25). It is becoming increasingly clear that the foreign-born are a heterogenous group. Primary care and infectious disease physicians, and diagnostic microbiology laboratories and indeed their foreign-born patients, would be well-served by a standardized nation-wide protocol for postarrival health assessment, adapted for specific immigrant and refugee populations.
13. Zencovich M, Kennedy K, MacPherson DW, Gushulak BD. Immigration medical screening and HIV infection in Canada. Int J STD AIDS 2006;17:813-6.

14. Posey DL, Blackburn BG, Weinberg M, et al. High prevalence and presumptive treatment of schistosomiasis and stronyloidiasis among African refugees. Clin Infect Dis 2007;45:1310-5.

15. Pardo J, Carranza C, Muro A, et al. Helminth-related eosinophilia in African immigrants, Gran Canaria. Emerg Infect Dis 2006;12:1587-9.

16. Roca C, Balanzó X, Gascón J, et al. Comparative, clinicoepidemiologic study of Schistosoma mansoni infections in travelers and immigrants in Spain. Eur J Microbiol Infect Dis 2002;21:219-23.

17. Kameh D, Smith A, Brock MS, Ndubisi B, Masood S. Female genital schistosomiasis: Case report and review of the literature. South Med J 2004;97:525-7.

18. Sarner L, Fakoya AO, Tawana C, et al. The utility of screening for parasitic infections in HIV-1-infected Africans with eosinophilia in London. Int J STD AIDS 2007;18:626-9.

19. Sudarshi S, Stümpfle R, Armstrong M, et al. Clinical presentation and diagnostic sensitivity of laboratory tests for Strongyloides stercoralis in travelers compared with immigrants in a non-endemic country. Trop Med Int Health 2003;8:728-32.

20. Keystone JS. Can one afford not to screen for parasites in high-risk immigrant populations? Clin Infect Dis 2007:45:1316-8.

21. Patel S, Parsyan AE, Gunn J, et al. Risk of progression to active tuberculosis among foreign-born persons with latent tuberculosis. Chest 2007;131:1811-6.

22. Laifer G, Widmer AF, Simcock M, et al. TB in a low-incidence country: Differences between new immigrants, foreign-born residents and native residents. Am J Med 2007;120:350-6.

23. Schwartzman K, Menzies D. Tuberculosis screening of immigrants to low-prevalence countries. A cost-effectiveness analysis. Am J Respir Crit Care Med 2000;161:780-9.

24. Citizenship and Immigration Canada. Medical exam requirements for permanent residents. $<$ http://www.cic.gc.ca/english/information/ medical/medexams-perm.asp> (Version current at July 8, 2008).

25. Gushulak BD, MacPherson DW. Globalization of infectious diseases: The impact of migration. Clin Infect Dis 2004;38:1742-8. 


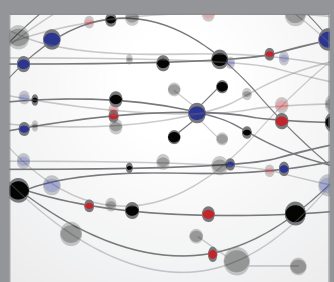

The Scientific World Journal
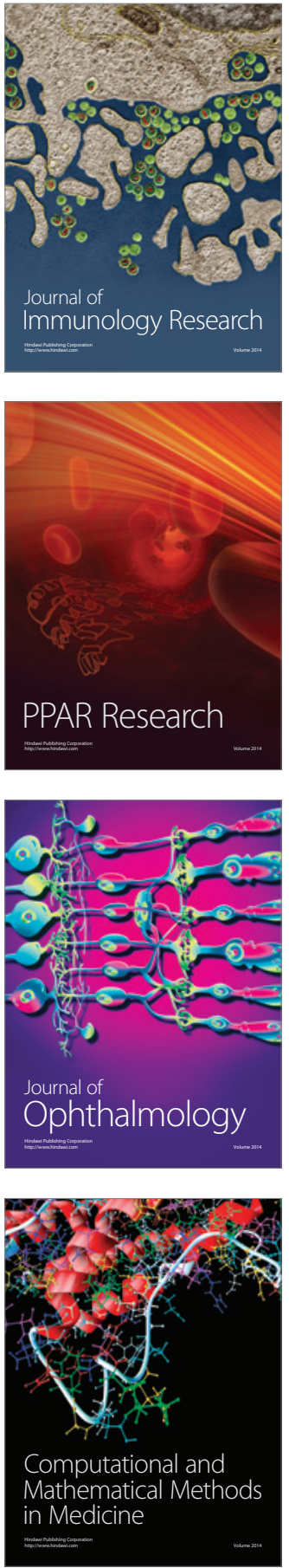

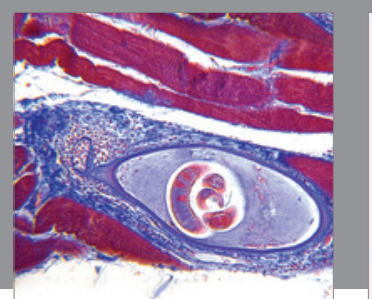

Gastroenterology Research and Practice

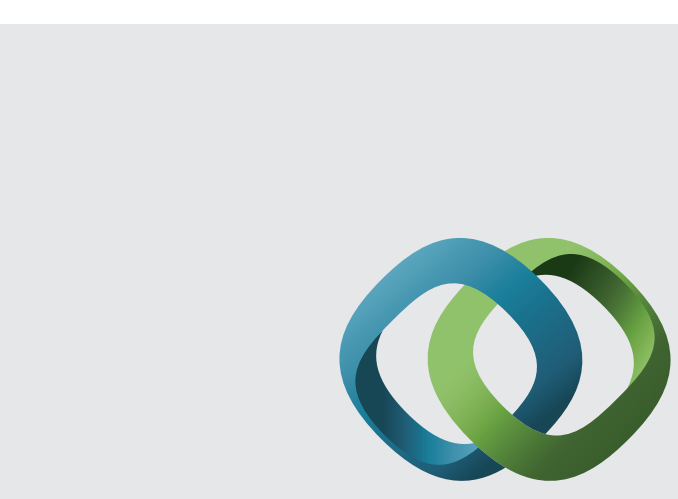

\section{Hindawi}

Submit your manuscripts at

http://www.hindawi.com
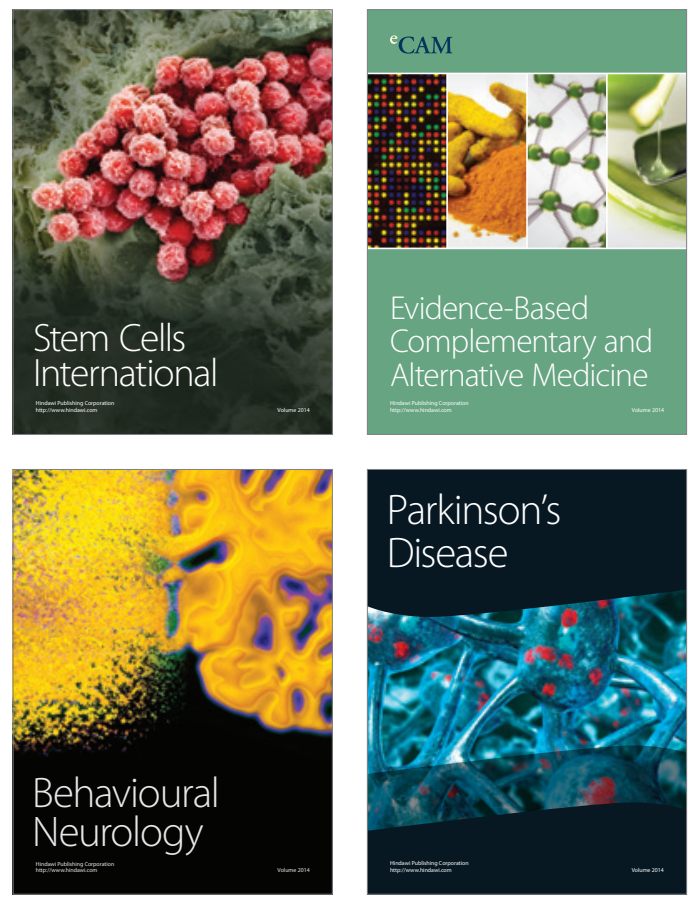
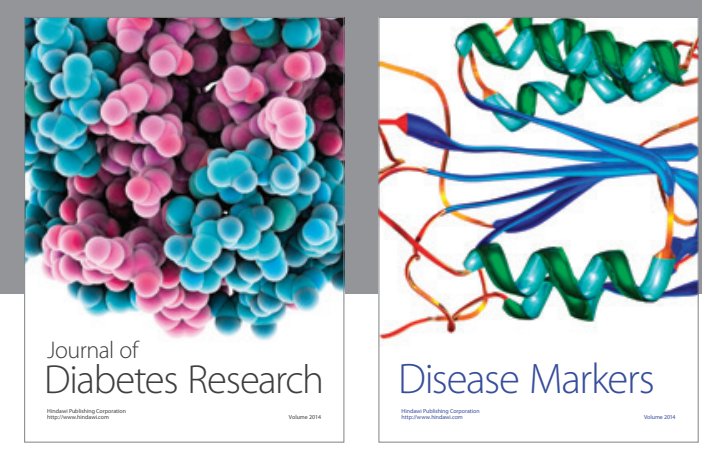

Disease Markers
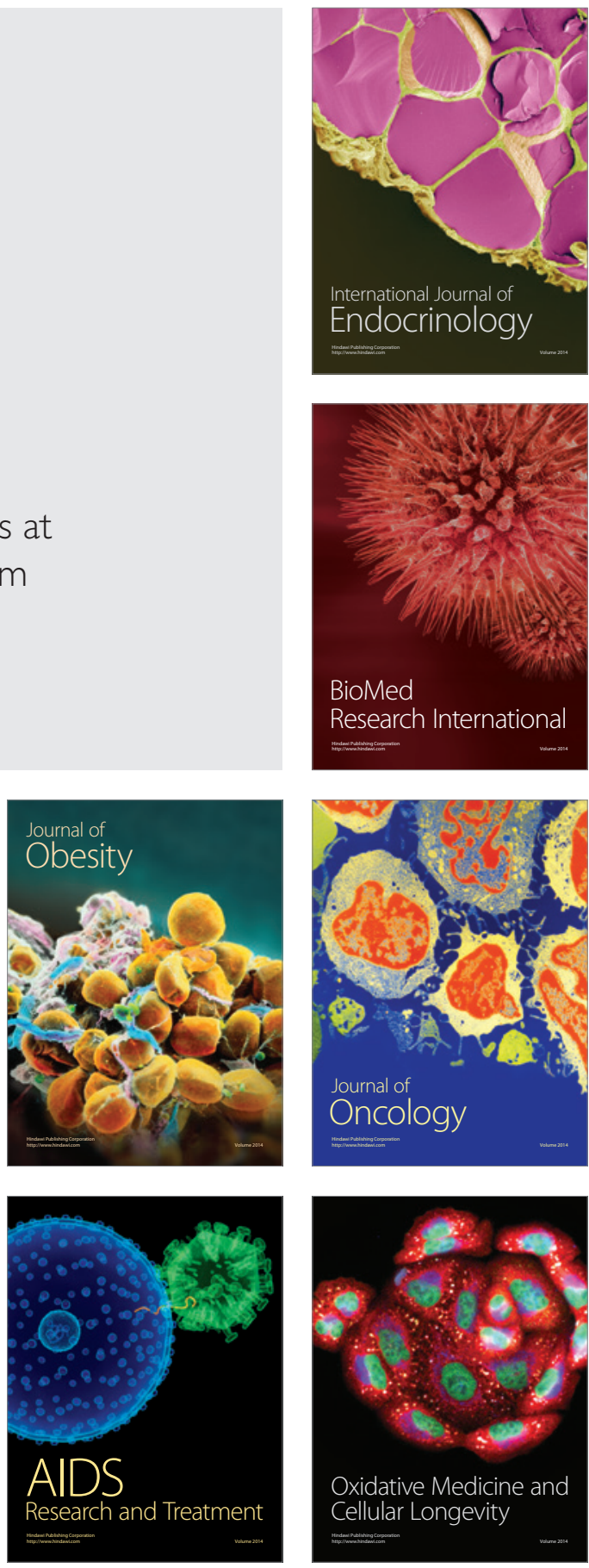